\title{
Problem of Traffic Congestion and Correlation Analysis of Driving behaviors in Qasimabad, Hyderabad
}

\author{
SUMRA ARAIN*, FAHAD AHMED SHAIKH*, AND MUHAMMAD MUJTABA SHAIKH** \\ RECEIVED ON 04.03.2016 ACCEPTED ON 16.08.2016 \\ ABSTRACT
}

In this study, we explore the problem of traffic congestion, its effects and related issues for Qasimabad, Hyderabad, Pakistan. The study is based on survey conducted at different sites of Qasimabad. The data was collected using a Questionnaire comprising of questions associated with traffic congestion and its causes. The data was analyzed with SPSS software. A main objective of this work is to present extent to which different driving behaviors are associated with each other. This is achieved using correlation analysis. Finally, recommendations to avoid transportation issues and traffic congestion in Qasimabad, Hyderabad based on present analysis are provided.

Key Words: Traffic Congestion, Correlation Analysis, Driving Behaviors.

\section{INTRODUCTION}

$\longrightarrow$ asimabad is one of the rapidly growing towns and taluka of Hyderabad. According to 1998 census the population of Qasimabad was 115,374. It has been increased during manifold of the last decades, as migration has occurred from rural Sindh to Hyderabad and specifically in Qasimabad. The growth in rural influx is one of the direct challenges to infrastructure and services in urban areas. One of the consequent problems in this regard is Traffic congestion. Due to traffic congestion, the environmental issues have been increased and on other side the increase in the decline of basic urban resources such as infrastructure and transportation are observed.

Traffic congestion refers to the critical situation when at some time the ongoing flow of vehicles exceeds the maximum capacity of roads. In such situation it is difficult to let the traffic flow which consequently results in Traffic Jam. In smart cities, the goal of urban planning is not only to deal with the usual recurring traffic congestion - that occurs frequently and can be avoided by planning measures - but to also provide alternative ways to let the traffic flow in usual during the non-recurring traffic jams. The latter are caused due to accidents and are random in occurrence [1]. However, the former type of traffic congestion, which occurs mainly at peak hours and because of lack of implementation of traffic rules can be managed using optimal transportation policies. Besides, the quality of traffic roads and behaviors of drivers while they drive are also important factors causing traffic congestion [2]. 
Qureshi, et. al. [3] advised to formulate a master plan to deal with the issue of urban transportation in Karachi and recommended a motor-free transport system, for pedestrians and bicyclers, which maintains environmental rights and social needs of public. Besides, assuring affordable fares, measures to restrict private vehicles and traffic management can also be done to tackle traffic congestion. Matin, et. al. [4], studied factors affecting economy due to traffic jam in Karachi. In order to reduce the traffic growth, it was suggested to minimize the use of private transport and promote public transport like circular rail or transit transport.

For a better guidance of land redevelopment of China, a study highlighted the need to find the reason causing traffic congestion after urban land redevelopment and provide some corresponding countermeasures [5]. The Traffic congestion factors are categorized into micro and macro level factors. The micro-level factors are related to traffic on road while the macro factors are related overall traffic need for road use. The congestion caused on microlevel (road) is driven by macro-level factors [6].

Recent works have also highlighted that there may be association between the driving behaviors and traffic congestion in a particular area. Stavrinos et. al. [7] investigated such association by examining under different road conditions and traffic congestion the behavior of young adults while they were driving. They also investigated the possible effect of using mobile phones and texting while driving. They argued that traffic congestion may also be caused due to inefficiency while driving. Xu et. al. [8], studied the situational factors and impulsiveness that may influence drivers to violate traffic rules. Hallmark et. al. [9], analyzed driver performance and behavior in traffic safety.

In Qasimabad, narrow roads, slow speeding, frequent trip times, and increasing line up of vehicles shows a major problem of traffic congestion due to which the commuters get frustrated. At worst, this situation also causes serious health problems, for inhabitants due to air and noise pollution caused by traffic congestion [10].

Due to rapid increase in population, the vehicular traffic also increases which is difficult to manage by the traffic authorities because roads have not the capacity to accommodate the current traffic so there is an immediate need to resolve the traffic related problems otherwise it can cause severe problems for the residents of Qasimabad in upcoming years.

In this work we have attempted to study traffic congestion issues of Qasimabad, Hyderabad by giving special focus to driving behaviors of drivers while they drive. Statistical analysis of different driving behaviors is carried out and strong correlation among few behaviors is noticed. It is necessary to encourage people to follow the traffic rules which will bring great change to resolve the issue of traffic congestion in cities. We show that there is an urgent need to implement the transportation policy in Qasimabad in prior because traffic congestion is ruining the available infrastructure and making the road conditions worst with the time. Also that the traffic congestion has caused drivers violate the traffic rules and vice-versa. Finally, we provide recommendations for transportation system of Qasimabad, to reduce traffic congestion.

\section{MATERIALS AND METHOD}

\subsection{Survey and Data Collection}

In order to know the best about traffic congestion issues, quality of roads, availability of private transport and driving behaviors, we surveyed different regions of Qasimabad. Based on recommendations from previous studies and interviews of traffic officers a short Questionnaire was designed to get responses from the public regarding these issues in form of a short closed as

Mehran University Research Journal of Engineering \& Technology, Volume 36, No. 1, January, 2017 [p-ISSN: 0254-7821, e-ISSN: 2413-7219] 
well as open-ended questions. The collected data was analyzed using SPSS software and proper correlation results were obtained.

Figs. 1-5 show some images of traffic congested areas of Qasimabad, these are helpful in understanding and analyzing the problems regarding traffic congestion and to present the real state of traffic related of Qasimabad. Fig. 1 shows that despite availability of the traffic signals, commuters are not following any rule and all the commuters are driving on road at once. Fig. 2 presents an example to the poor condition of roads in Qasimabad, road is not paved and not in good condition due to which rain water on road creates difficulties for commuters. Mostly, the illegal encroachments, throwing of solid waste and garbage on roads, destroying the physical condition of road and impairing road's stability bring decrease in the life of road and are the main factors determining poor condition of roads. Fig. 3 depicts congestion at Naseem Nagar road, because less part of road is paved and rest of the road is unpaved and covered with on street parking of building residents, which is being the cause of traffic congestion on road. Fig. 4 depicts that there is no any traffic signal and traffic police at roundabout of Ali Palace, hence traffic congestion occurs at peak hours. Fig. 5 represents traffic congestion on road at Naseem Nagar. Traffic signal and traffic police both are not available due to which commuters are not following any rule hence traffic congestion occurs whole day at this route.

Table 1 shows the distribution of all 100 participants with respect to the different locations at Qasimabad, Hyderabad in the survey through questionnaire.

We focused on main areas of Qasimabad, Hyderabad while data collection. Fig. 6 shows the location map of the study area with four main locations highlighted. The road network map of Qasimabad, Hyderabad with four location highlighted is shown in Fig. 7.

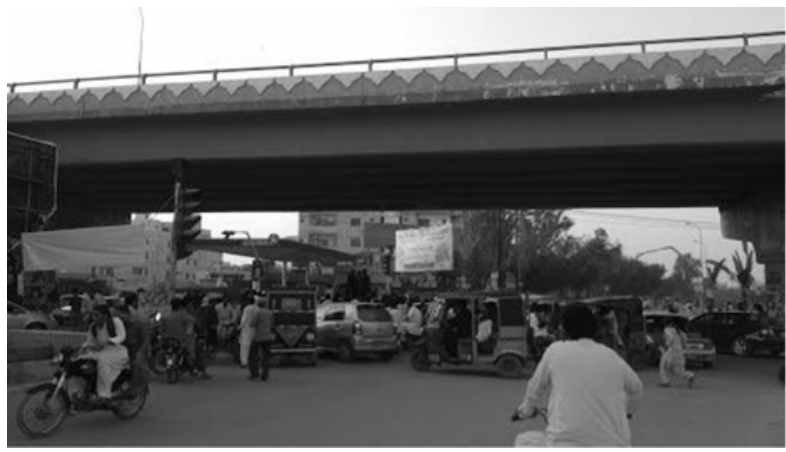

FIG. 1. TRAFFIC CONGESTION AT POONAM CHOWK, QASIMABAD

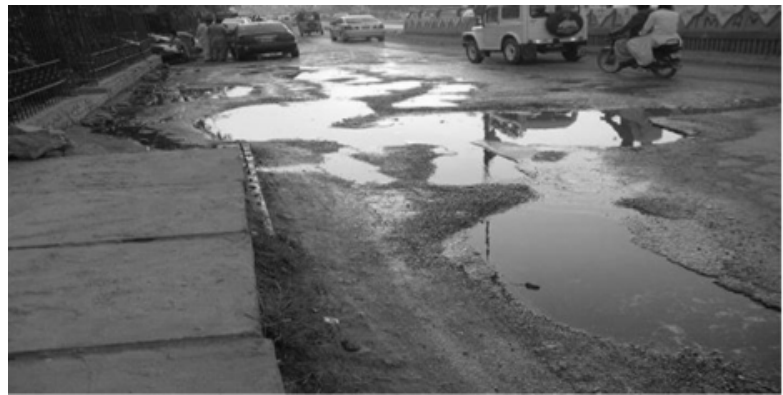

FIG. 2. POOR CONDITION OF ROAD IN QASIMABAD

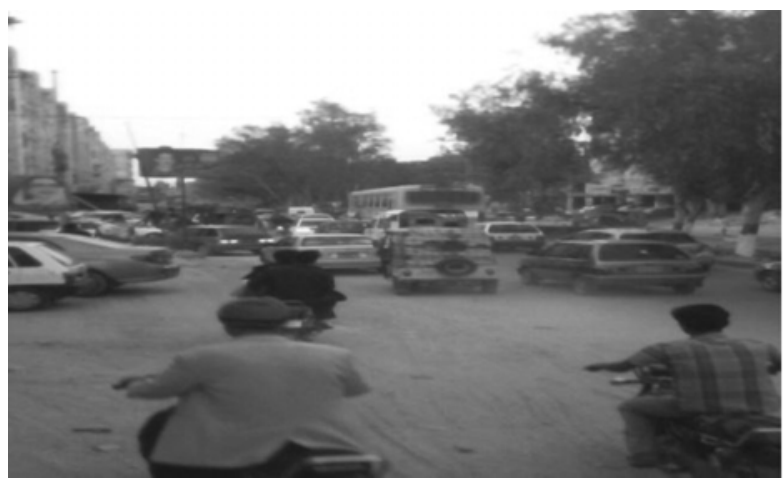

FIG. 3. TRAFFIC CONGESTION ON NASEEM NAGAR ROAD

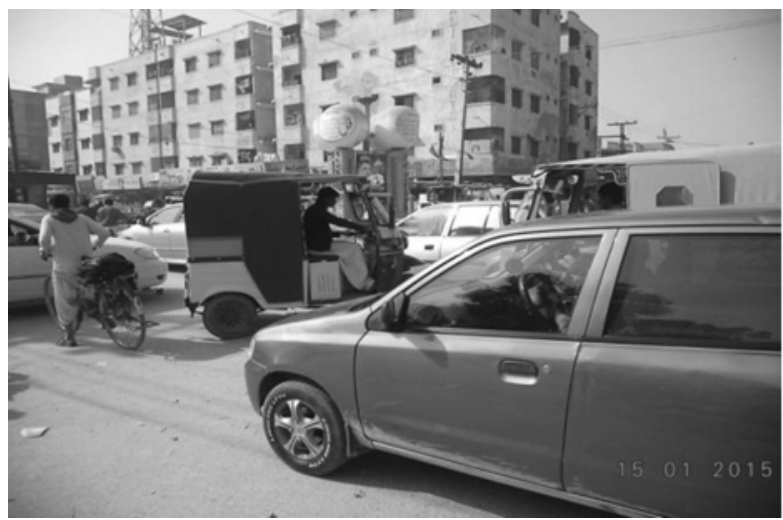

FIG. 4. TRAFFIC CONGESTION OCCURS AT PEAK HOURS

Mehran University Research Journal of Engineering \& Technology, Volume 36, No. 1, January, 2017 [p-ISSN: 0254-7821, e-ISSN: 2413-7219] 


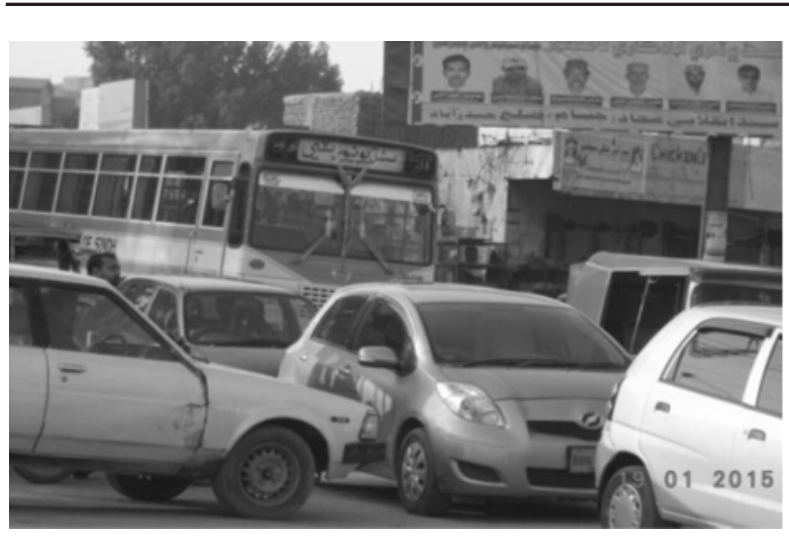

FIG.5. TRAFFIC CONGESTION ON ROAD AT NASEEM NAGAR

TABLE 1. LOCATIONS OF RESPONDENTS

\begin{tabular}{|c|c|c|}
\hline No. & Location & Frequency (\%) \\
\hline 1. & Pakora Stop & 22.00 \\
\hline 2. & Ali Palace & 22.00 \\
\hline 3. & Naseem Nagar & 39.00 \\
\hline 4. & Poonam Chowk & 17.00 \\
\hline \multicolumn{2}{|c|}{ Total } & 100.00 \\
\hline
\end{tabular}

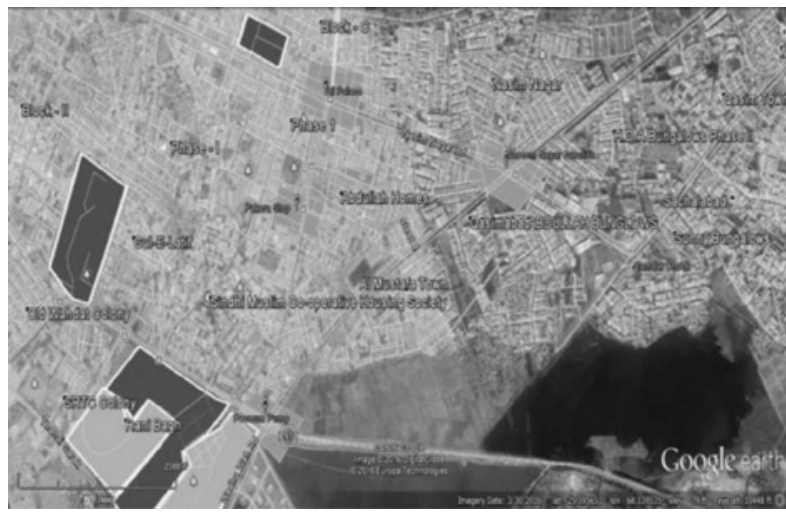

FIG. 6. LOCATION MAP OF STUDY AREAS OF QASIMABAD

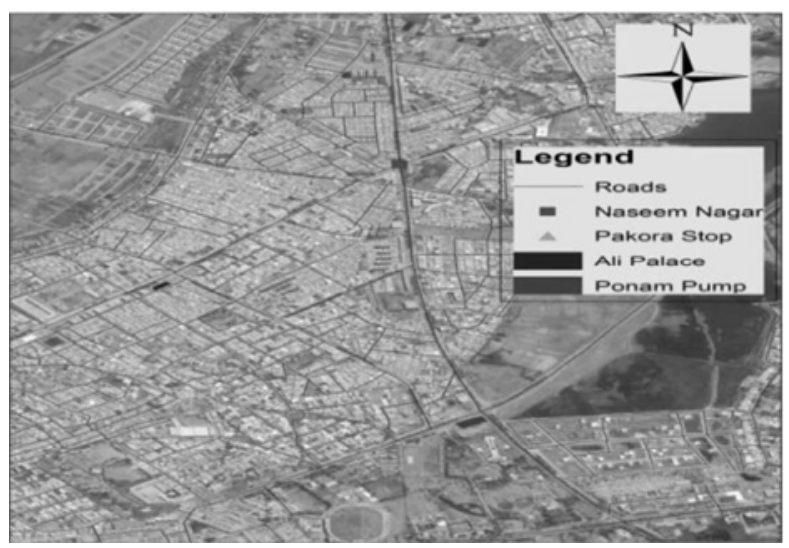

FIG. 7. ROAD NETWORK MAP OF QASIMABAD
Following questions were asked and responses were obtained to study traffic congestion and driving behaviors in Qasimabad, Hyderabad:

Question-1: Do you agree that there is traffic congestion in Qasimabad?

Question-2: What is the reason behind traffic congestion in your opinion?

Question-3: What health problems are caused due to traffic congestion?

Question-4: What type of pollution is caused due to traffic congestion?

Question-5: What main problem is faced by drivers while driving in the study region?

Question-6: What is the reason that people avoid shopping in congested areas?

Question-7: Is there any public transport for the public in your area?

Question-8: What is the mode of transport you use?

Question-9: What is condition of roads in study area?

Question-10: What are the driving behaviors of drivers while they drive in your area?

Question-11: How late do you reach at your destination due to traffic jam?

The details regarding gender, age group and occupation of the respondents were also obtained and are shown in Figs. 8-10, respectively.

\section{RESULTS AND DISCUSSION}

In response to first question, all 100 respondents answered that they agree that there is traffic congestion in study area, Qasimabad. Table 2 shows, according to 
respondents, what had been the possible reason behind traffic congestion. According to the respondents, the narrow roads, damage roads, encroachments on the roads and absence of traffic police and unavailability of traffic signals are the major reasons of traffic congestion on the roads of Qasimabad.

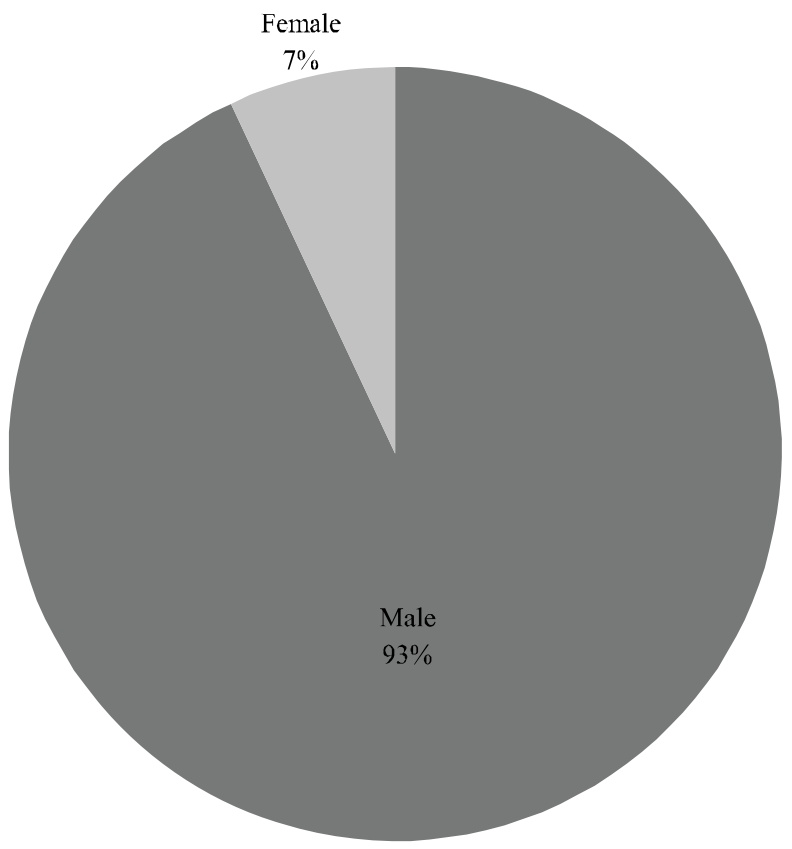

FIG. 8. GENDER OF RESPONDENTS

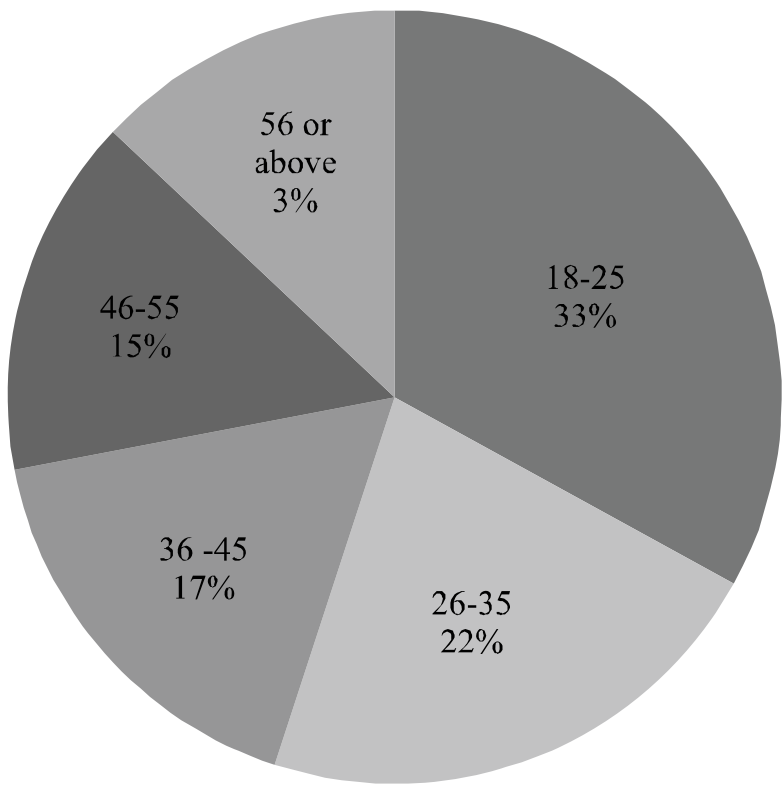

FIG. 9. AGE GROUP OF RESPONDENTS (IN YEARS)
Most of the respondents out of 100 responded that Depression/Irritation, Stress and Lungs Problems are the major health problems cause by traffic congestion. This is shown in Table 3. On the other hand Table 4 shows that out of 100 respondents, most of the respondents, i.e. 87 answered that air pollution is caused more due to traffic

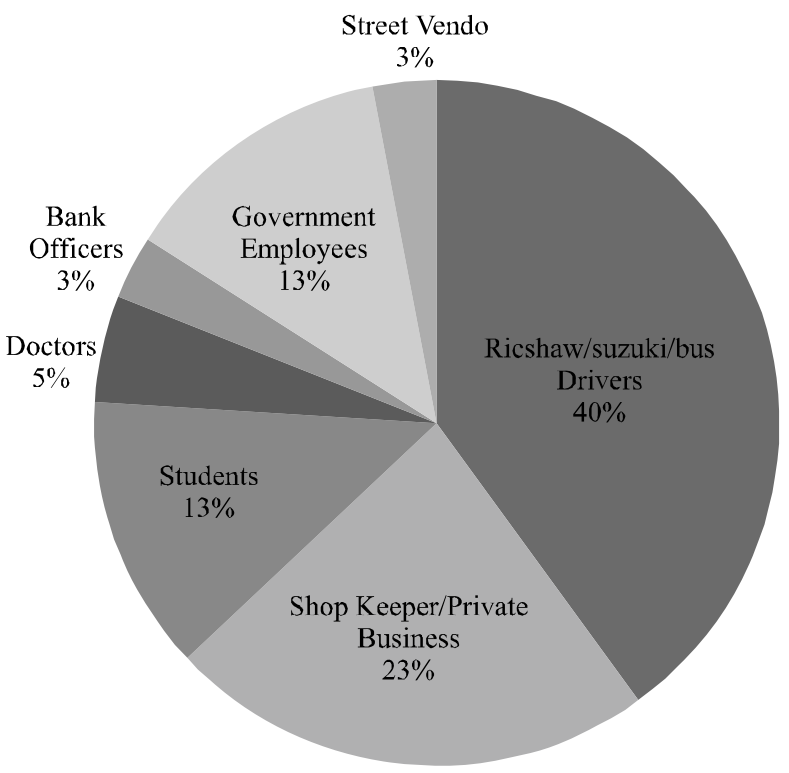

FIG. 10. OCCUPATION OF RESPONDENTS

TABLE 2. REASONS OF TRAFFIC CONGESTION (QUESTION-2)

\begin{tabular}{|c|c|c|}
\hline Reasons of Traffic Congestion & Agree & Disagree \\
\hline Narrow Roads & 46 & 54 \\
\hline Damage Roads & 56 & 44 \\
\hline Encroachment On The Roads & 51 & 49 \\
\hline Unavailability Of Traffic Signal & 34 & 66 \\
\hline $\begin{array}{c}\text { Lack Of Transportation Planning } \\
\text { More Use Of Private Vehicle }\end{array}$ & 19 & 81 \\
\hline $\begin{array}{c}\text { Instead Of Public Transport } \\
\text { Absence Of Traffic Police }\end{array}$ & 34 & 86 \\
\hline Unavailability Of Pedestrians Path & 13 & 75 \\
\hline $\begin{array}{c}\text { Delayed In Repairing Of Road } \\
\text { Works }\end{array}$ & 7 & 86 \\
\hline People Use Wrong Way & 7 & 93 \\
\hline
\end{tabular}

Mehran University Research Journal of Engineering \& Technology, Volume 36, No. 1, January, 2017 [p-ISSN: 0254-7821, e-ISSN: 2413-7219] 
congestion, only 10 respondents answered noise pollution and negligible respondents replied water pollution, according to sample data.

Table 5 illustrates that out of 100 people surveyed, 74 respondents replied that drivers face problem of traffic jam, 17 respondents reported that the unsafe crossing points was the driving problem, 8 respondents face the problem of on street parking and only 1 respondent answered that the lack of pedestrian crossing while they drive is the problem and leads to traffic congestion.

TABLE 3. EFFECTS OF TRAFFIC CONGESTION ON THE HEALTH OF RESPONDENTS (QUESTION-3)

\begin{tabular}{|c|c|}
\hline Health Problems & Frequency (\%) \\
\hline Depression/Irritation & 18.00 \\
\hline Stress & 24.00 \\
\hline Lungs Problems & 25.00 \\
\hline Breathing problems & 8.00 \\
\hline Headache & 7.00 \\
\hline High/ Low blood pressur & 9.00 \\
\hline Asthma & 5.00 \\
\hline No effect & 4.00 \\
\hline Total & 100.00 \\
\hline
\end{tabular}

TABLE 4. TYPE OF POLLUTION (QUESTION-4)

\begin{tabular}{|c|c|}
\hline Types of Pollution & Frequency (\%) \\
\hline Air pollution & 87.00 \\
\hline Water pollution & 03.00 \\
\hline Noise pollution & 10.00 \\
\hline Total & 100.00 \\
\hline
\end{tabular}

TABLE 5. PROBLEMS FACED BY DRIVERS (QUESTION-5)

\begin{tabular}{|c|c|}
\hline Problems & Frequency (\%) \\
\hline Traffic jam & 74.00 \\
\hline Unsafe crossing points & 17.00 \\
\hline On street parking & 08.00 \\
\hline Lack of pedestrians way & 01.00 \\
\hline Total & 100.00 \\
\hline
\end{tabular}

Out of 100 participants in sample, 70 people avoid shopping in congested areas due to traffic jam in main commercial areas and 19 people respond that they avoid shopping due to unavailability of parking space in main commercial areas. Rests of the respondents choose other given options. This is described in Table 6. It should be noted that $70 \%$ respondents answered, they do not have any provision of public transport in study area. This shows that people frequently use private vehicles which lead to traffic congestion.

Table 7 represents that out of 100 people surveyed most of the respondents have car, motor cycle and rickshaw for their personal mode of transport, which is showing that people travel more by private vehicle instead of public transport. Table 8 represents that 30 respondents responded partial good, 30 respondents responded bad, 14 respondents answered good and 26 respondents replied worst for the condition of roads in study area. The main reasons while describing quality of roads form good to worst had been extent of encroachment, presence of solid waste and garbage and physical quality of road (paved finely or damaged, etc.). Based on these factors the respondents were instructed to select a response to Question-9.

Table 9 depicts, 72 respondents answered that drivers drive dangerously, 69 respondents replied that drivers drive without care and attention, 72 responded that drivers drive without reasonable consideration for other road users and only 23 responded that drivers follow rules while they drive. Usually drivers do not follow the traffic rules, according to sample data.

TABLE 6. REASONS WHY PEOPLE AVOID SHOPPING IN CONGESTED AREAS (QUESTION-6)

\begin{tabular}{|c|c|}
\hline Reasons & Frequency (\%) \\
\hline Due to traffic jam in main commercial areas & 70.00 \\
\hline Space not available for pedestrians & 09.00 \\
\hline unavailability of parking space & 19.00 \\
\hline $\begin{array}{c}\text { More use of private vehicle in congested } \\
\text { areas }\end{array}$ & 02.00 \\
\hline Total & 100.00 \\
\hline
\end{tabular}

Mehran University Research Journal of Engineering \& Technology, Volume 36, No. 1, January, 2017 [p-ISSN: 0254-7821, e-ISSN: 2413-7219] 
Table 10 shows that out of 100 people surveyed most of the respondents answered that they reach late approximately 16-30 minutes per trip at their destination due to the traffic congestion; results are according to sample data.

TABLE 7. RESPONDENTS MODE OF TRANSPORT (QUESTION-8)

\begin{tabular}{|c|c|}
\hline Mode of Transport & Frequency (\%) \\
\hline Motor cycle/ Scooter & 28.00 \\
\hline Personal car & 38.00 \\
\hline Auto/ Tempo & 02.00 \\
\hline Bus & 04.00 \\
\hline Rickshaw & 23.00 \\
\hline Cycle & 01.00 \\
\hline Suzuki & 04.00 \\
\hline Total & 100.0 \\
\hline
\end{tabular}

TABLE 8. CONDITION OF ROADS IN STUDY AREA (QUESTION-9)

\begin{tabular}{|c|c|}
\hline Condition of Road & Frequency (\%) \\
\hline Good & 14.00 \\
\hline Partial good & 30.00 \\
\hline Bad & 30.00 \\
\hline Worst & 26.00 \\
\hline Total & 100.00 \\
\hline
\end{tabular}

TABLE 9. DRIVING BEHAVIORS OF DRIVERS (QUESTION-10)

\begin{tabular}{|c|c|c|}
\hline Driving Behaviors & Yes & No \\
\hline Follow Rules & 23 & 77 \\
\hline Drive Dangerously & 72 & 28 \\
\hline $\begin{array}{c}\text { Drive Without Care } \\
\text { And Attention }\end{array}$ & 69 & 31 \\
\hline $\begin{array}{c}\text { Drive Without Reasonable } \\
\text { Consideration For Other Road } \\
\text { Users }\end{array}$ & 75 & 25 \\
\hline
\end{tabular}

TABLE 10. THE TIME DELAYED WHILE REACHING THE DESTINATION DUE TO TRAFFIC JAM (QUESTION-11)

\begin{tabular}{|c|c|}
\hline Time Period & Frequency (\%) \\
\hline $0-15$ minutes & 30.00 \\
\hline $16-30$ minutes & 42.00 \\
\hline $31-41$ minutes & 17.00 \\
\hline 46 or more & 11.00 \\
\hline Total & 100.00 \\
\hline
\end{tabular}

\subsection{Correlation Analysis of Different Driving behaviors}

One of the main objectives of this study is to find extent to which different driving behaviors are correlated with each other. For this, we name the four driving behaviors from Table 9 as follows:
X1: $\quad$ Follow rules
X2: $\quad$ Drive dangerously
X3: Drive without care and attention
X4: Drive without reasonable consideration for other road users.

It should be noted that for the purpose of obtaining the best responses for Question-10 of the Questionnaire and hence to generate representative data for correlation analysis, the explanation on different driving behaviors as in Table 9 was made explicit to the respondents before acquiring their answers. The option stating "Follow Rules" (X1) referred to whether the drivers in the study area: either motor cycle or car drivers follow the traffic rules and regulations or not. The option "Drive Dangerously" attempted to note the response on whether or not the drivers drive dangerously in the study area. In the third option, also labeled as X3, commuters were supposed to say Yes or No about the care and attention of drivers during driving i.e. either they pay full attention on driving or not. The negation in this case may include the use of loud system in the vehicles or use of mobile phone while driving which is dangerous not only for driver himself but for others too. In last option, labeled as X4, it was asked about drivers' consideration for other road users i.e. the pedestrians, bicyclers, disabled people and for slow moving vehicles like, for example donkey cart, etc.

The coefficient of correlation using the 100 sample responses to see association between the behaviors X1$\mathrm{X} 4$ may be defined as: 


$$
r_{i j}=\frac{100 \sum X_{i} X_{j}-\sum X_{i} \cdot \sum X_{j}}{\sqrt{\left[100 \sum X_{i}^{2}-\left(\sum X_{i}\right)^{2}\right] \cdot\left[100 \sum X_{j}^{2}-\left(\sum X_{j}\right)^{2}\right]}}
$$

where $\mathrm{i}$ and $\mathrm{j}$ are not same.

Using formula from Equation (1) on each possible pair of 100 responses on driving behaviors, the obtained correlation coefficients and significance levels are reported in Table 11.

The results from Table 11 can be interpreted as follows:

Case-1 Comparison of those who follow rules and drive dangerously shows weak negative correlation with only $23 \%$ confidence and with high level of significance $77 \%$, with this result we can say that those who follow rules do not drive dangerously.

Case-2 Comparisons of those who follow rules and drive without care and attention shows negative correlation, with $95 \%$ confidence. With this result we can say that those who follow rules do not drive without care and attention.

Case-3 Comparison of those who follow rules and drive without reasonable consideration for other road users shows weak positive correlation with $31.6 \%$ confidence and with high level of significance $68.4 \%$, with this result we can say that, those who follow rules also drive without reasonable consideration for other road users, according to sample data.

TABLE 11. ANALYSIS OF DRIVING BEHAVIORS OF DRIVERS WHILE THEY DRIVE

\begin{tabular}{|c|c|c|c|c|c|}
\hline Case & $\mathrm{i}$ & $\mathrm{j}$ & $\mathrm{r}_{\mathrm{ij}}$ & Significance Level & $\begin{array}{c}\text { Confidence Level } \\
(\%)\end{array}$ \\
\hline 1 & $\mathrm{X} 1$ & $\mathrm{X} 2$ & -0.03 & 0.77 & 23 \\
\hline 2 & $\mathrm{X} 1$ & $\mathrm{X} 3$ & -0.19 & 0.04 & 95 \\
\hline 3 & $\mathrm{X} 1$ & $\mathrm{X} 4$ & 0.04 & 0.68 & 31.6 \\
\hline 4 & $\mathrm{X} 2$ & $\mathrm{X} 3$ & 0.73 & 0.00 & 100 \\
\hline 5 & $\mathrm{X} 2$ & $\mathrm{X} 4$ & 0.77 & 0.00 & 100 \\
\hline 6 & $\mathrm{X} 3$ & $\mathrm{X} 4$ & 0.71 & 0.00 & 100 \\
\hline
\end{tabular}

Case-4 Comparisons of those who drive dangerously and drive without care and attention shows strong positive correlation with $100 \%$ of confidence; we can say that those who drive dangerously also drive without care and attention, according to sample data.

Case-5 Comparisons of those who drive dangerously and drive without reasonable consideration for other road users showing strong positive correlation with $100 \%$ confidence; we can say that those who drive dangerously also drive without reasonable consideration for other road users, according to sample data.

Case-6 Comparisons of those who drive without care and attention and drive without reasonable consideration for other road users shows strong positive correlation with $100 \%$ confidence; we can say that those who drive without care and attention also drive without reasonable consideration for other road users, according to sample data.

\section{CONCLUSIONS}

The problem of traffic congestion was discussed by surveying 100 people from different areas of Qasimabad, Hyderabad. Their responses to different problems associated with traffic congestion were discussed. Finally, it was shown through correlation analysis that the different driving behaviors of drivers while they drive are also inter-dependent. The results by correlation analysis are in good agreement with the general views of public.

In recent years, there have been some efforts to enhance traffic system in Pakistan and to manage transportation issues in cities, but due to poor coordination between 
departments being a cause of these rapidly growing traffic problems. Government should also ascertain the implementation of traffic rules and manage unlawful driving behaviors. While the cities like Islamabad, Lahore and Karachi have improved transportation system and taken steps to minimize traffic congestion, still the traffic congestion is a critical issue in most of the regions of Pakistan.

The recommendations from this study may be summarized as follows:

(i) The capacity of road (supply) should according to the increasing vehicles (demand).

(ii) Road network and traffic management plans should be updated periodically, as per the requirement.

(iii) Construction and repairing of road works should be done during night times, otherwise must be avoided in peak hours.

(iv) Maintenance of roads in Qasimabad should be on bi-annual basis.

(v) Drainage system of roads should properly be maintained because in rainy days rain water on roads cause traffic congestion and reduce the life and stability of road.

(vi) Vehicles involved in accidents or mechanical failures should be removed from roads as quickly as possible by providing required services to avoid congestion on road.

(vii) Removal of illegal encroachments on roads by development authorities.

(viii) Few buses and Suzuki's are available for public in Qasimabad on limited routes; authority should introduce active public transport system in Qasimabad, which should cover all the major routes.

(ix) Educational institutions, hospitals, public places should be located away from busy roads to avoid increase in traffic.

(x) Restrict peak-hour curbside parking on congested streets.

(xi) Public and private institutions, whether health or education, should have their own parking spaces as required.

(xii) Government should use new advance technology system to trace those vehicles that disobey rules.

(xiii) Authority should formulate and enforce urban transportation laws and policies.

(xiv) Process of giving driving license should proceed strictly after taking driving and written test to prevent road accidents.

(xv) The construction of any new high risen buildings and shopping centers should be restricted at areas with existing congestion problems.

(xvi) High risen buildings and shopping centers should have more than one opening gates to prevent the burden of traffic on one side of road.

\section{ACKNOWLEDGEMENTS}

Authors are indebted to referee for useful comments that have led to improvements in final draft of this paper. Participation and assistance by Ms. Nosheen Arain, Ms. Anum Gul, Mr. Kamlesh Kumar, Mr. Rana Nasir and Mr. Kamran Memon, are highly appreciated while conducting the survey.

Mehran University Research Journal of Engineering \& Technology, Volume 36, No. 1, January, 2017 [p-ISSN: 0254-7821, e-ISSN: 2413-7219] 


\section{REFERENCES}

[1] Logi, F., and Ritchie, S. G., "Development and Evaluation of a Knowledge-Based System for Traffic Congestion Management and Control", Transportation Research Part-C: Emerging Technologies, Volume 9, No. 6, pp. 433-459, 2001.

[2] Mun, S.I., "Traffic Jams and the Congestion Toll", Transportation Research Part-B: Methodological, Volume 28, No. 5, pp. 365-375, 1994.

[3] Qureshi, I.A., and Huapu, L.U., "Urban Transport and Sustainable Transport Strategies: A Case Study of Karachi, Pakistan", Tsinghua Science and Technology, Volume 12, pp. 309-317, 2007.

[4] Matin, F., Herani, G.M. and Warraich, U.A., "Factors Affecting Traffic Jam in Karachi and its Impact on Performance of Economy", KASBIT Business Journal, Volume 5, pp. 25-32, 2012. "Reasons and Countermeasures of Traffic Congestion under Urban Land Redevelopment", Procedia - Social and Behavioral Sciences, Volume 96, pp. 2164-2172, 2013.

[6] Chakrabartty, A., and Gupta, S., "Traffic Congestion in the Metropolitan City of Kolkata", Journal of Infrastructure Development, 2014.

[7] Stavrinos, D., Jones, J.L., Garner, A.A., Griffin, R., Franklin, C.A., Ball, D., and Fine, P.R., "Impact of Distracted Driving on Safety and Traffic Flow", Accident Analysis \& Prevention, Volume 61, pp. 63-70, 2013.

[8] Xu, Y., Li, Y., and Jiang, L., “The Effects of Situational Factors and Impulsiveness on Drivers' Intentions to Violate Traffic Rules: Difference of Driving Experience", Accident Analysis \& Prevention, Volume 62, pp. 54-62, 2014.

[9] Hallmark, S., McGehee, D., Bauer, K.M., Hutton, J.M., Davis, G.A., Hourdos, J., and Rootzen, H., "Initial Analyses from the SHRP 2 Naturalistic Driving Study: Addressing Driver Performance and Behavior in Traffic Safety (No. SHRP 2 Safety Project S08), 2013.

[10] Altshore, A., "The Changing Pattern Policy: The Decision Making Environment of Urban Transportation", Public Policy, Volume 25, pp. 171-203, 1977. 